\title{
Four multifaceted countrywide campaigns to promote hand hygiene in Belgian hospitals between 2005 and 2011: impact on compliance to hand hygiene
}

M Costers (michiel.costers@health.fgov.be) ${ }^{1}$, N Viseur², B Catry ${ }^{2}$, A Simon ${ }^{3}$

1. Federal Public Service Health, Food Chain Safety and Environment, Belgian Antibiotic Policy Coordination Committee; Brussels, Belgium

2. Scientific Institute of Public Health, Healthcare Associated Infections and Antimicrobial Resistance; Brussels, Belgium

3. University Hospital Saint Luc UCL, Department of Microbiology and Infection Control; Brussels, Belgium

Citation style for this article:

Costers M, Viseur N, Catry B, Simon A. Four multifaceted countrywide campaigns to promote hand hygiene in Belgian hospitals between 2005 and 2011 : impact on compliance to hand hygiene. Euro Surveill. 2012;17(18):pii=20161. Available online: http://www.eurosurveillance.org/ViewArticle.aspx?Articleld=20161

Article submitted on 25 January 2012 / published on 3 May 2012

Four consecutive one-month campaigns were organised to promote hand hygiene in Belgian hospitals between 2005 and 2011. The campaigns included a combination of reminders in wards, educational sessions for healthcare workers, promotion of alcoholbased hand rub use, increasing patient awareness, and audits with performance feedback. Prior and after each one month intervention period, the infection control teams measured hand hygiene compliance of healthcare workers by direct observation using a standardised observation roster. A total of 738,367 opportunities for hand hygiene were observed over the four campaigns. Compliance with hand hygiene significantly increased from $49.6 \%$ before to $68.6 \%$ after the intervention period for the first, from $53.2 \%$ to $69.5 \%$ for the second, from $58.0 \%$ to $69.1 \%$ for the third, and from $62.3 \%$ to $72.9 \%$ for the fourth campaign. The highest compliance rates were consistently observed in paediatric units. Compliance rates were always markedly lower among physicians than nurses. After patient contact and body fluid exposure risk, compliance rates were noticeably higher than before patient contact and performing aseptic procedures. We conclude that repeated countrywide campaigns to promote hand hygiene result in positive long-term outcomes. However, lower compliance rates among physicians compared with nurses, before patient contact, and before performing aseptic procedures remain challenges for future campaigns.

\section{Introduction}

Healthcare-associated infections (HAls) place a tremendous burden on public health resources. A national point prevalence survey performed by the Belgian Health Care Knowledge Centre (KCE) in 2007 revealed a prevalence rate of infected patients of $6.2 \%$ in Belgian acute care hospitals, which amounts to an estimated 103,000 infected patients in this setting, annually [1]. Based on these data and matched cohort studies, the yearly excess in-hospital stay, healthcare payer cost and in-hospital mortality for patients with HAls in Belgian acute care hospitals were estimated at 720,757 hospital-days, 384.3 million Euros and 2,625 deaths, respectively [2].

Transmission of microbial pathogens by the hands of healthcare workers (HCWs) during patient care plays a crucial role in the spread of HAls [3]. Hence, it is not surprising that hand hygiene is generally regarded as the most effective measure to prevent these infections, with several reports showing a temporal relation between interventions to improve hand hygiene practices, higher compliance rates and/or reduced infection rates [4-8]. However, numerous reports indicate that hand hygiene compliance of HCWs remains disappointingly low, with mean baseline rates ranging from $5 \%$ to $89 \%$, with an overall average of about $40 \%[4,5,9]$. The Federal Platform for Infection Control (FPIC), with the support of the Belgian Antibiotic Policy Coordination Committee (BAPCOC), was able to procure funding of 125,000 Euros per campaign from the Belgian federal government for four multifaceted countrywide campaigns to improve hand hygiene compliance in Belgian hospitals. A multidisciplinary working group was created to organise these campaigns.

We describe the organisation of the Belgian campaigns and present their impact on compliance to hand hygiene by the HCWs.

\section{Methods}

\section{Organisation of the campaigns}

All Belgian acute care, chronic care and psychiatric hospitals were invited by the Federal Public Service Health, Food Chain Safety and Environment to voluntarily participate in the national campaigns. Psychiatric hospitals were invited from the second campaign onwards. The infection control (IC) teams of the participating hospitals were responsible for the implementation 
of the campaign at their institution, and the working group organised workshops to inform the IC teams about the methodology of the campaigns and to provide training for measuring hand hygiene compliance.

Between 2005 and 2011, four campaigns were conducted, each lasting one month. The first campaign took place between 15 February and 15 March 2005, the second between 15 November and 15 December 2006, the third between 19 January and 13 February 2009, and the fourth between 14 February and 16 March 2011. The first three campaigns were launched by the Belgian Minister of Social Security and Public Health using press conferences. During the one-month intervention period of each campaign, the IC teams displayed or distributed campaign materials throughout their own institution and organised educational sessions for all HCWs. The IC teams were asked to measure hand hygiene compliance of HCWs by direct observation and to transfer these data to the Scientific Institute of Public Health (IPH). The observations before took place either in the weeks directly before the intervention (first campaign) or with an interval of one (second and third campaign) or two months (fourth campaign). The interval between the intervention and the observation of compliance after was one month (first and second campaign) or one and a half month (third and fourth campaign).

\section{Campaign materials}

The campaigns combined audits (with performance feedback), reminders in wards, educational sessions for HCWs, promotion of alcohol-based hand rub use, and information for patients. The campaign materials (Table 1) were provided free of charge to all participating institutions; they are available on the campaign website [10].

\section{TABLE 1}

Materials used in four consecutive countrywide campaigns to promote hand hygiene in hospitals, Belgium, 2005-2011

\begin{tabular}{|c|c|c|}
\hline Type of campaign material & Target group & $\begin{array}{l}\text { Campaign } \\
\text { number }^{\mathrm{a}}\end{array}$ \\
\hline \multicolumn{3}{|l|}{ Posters with different topics } \\
\hline Campaign slogan 'You are in good hands' & Healthcare workers and hospitalised patients & $1,2,3,4$ \\
\hline Indications for hand hygiene-'When' & Healthcare workers and hospitalised patients & $2,3,4$ \\
\hline Correct hand hygiene technique using alcohol based hand rub-'How' & Healthcare workers and hospitalised patients & $2,3,4$ \\
\hline Rationale for hand hygiene-'Why' & Healthcare workers and hospitalised patients & 3,4 \\
\hline Deleterious effect on hand hygiene of jewels and bad nail hygiene & Healthcare workers and hospitalised patients & 3,4 \\
\hline Indications for glove use & Healthcare workers and hospitalised patients & 3,4 \\
\hline Role model for other healthcare worker & Healthcare workers and hospitalised patients & 4 \\
\hline \multicolumn{3}{|l|}{ Leaflets for target groups } \\
\hline Hospitalised patients' leaflets - first version & Hospitalised patients & $1,2,3$ \\
\hline Healthcare workers' leaflets & Healthcare workers & 1 \\
\hline Physicians'leaflets & Physicians & 3,4 \\
\hline Hospitalised patients' leaflets - second version ${ }^{\mathrm{b}}$ & Hospitalised patients & 4 \\
\hline \multicolumn{3}{|l|}{ Educational material } \\
\hline Slide presentation for healthcare workers & Healthcare workers & $1,2,3,4$ \\
\hline Slide presentation specifically targeted at physicians & Physicians & 4 \\
\hline \multicolumn{3}{|l|}{ Gadgets with the campaign sloganc } \\
\hline Pins & Healthcare workers & 1 \\
\hline Badge holders & Healthcare workers & $2,3,4$ \\
\hline Bookmark & Hospitalised patients & 3 \\
\hline Magnets & Healthcare workers & 4 \\
\hline Web-based quiz on hand hygiene ${ }^{d}$ & Healthcare workers $^{d}$ & $2,3,4$ \\
\hline Video clips on hand hygiene for hospital video circuit $(n=2)$ & Healthcare workers and hospitalised patients & 4 \\
\hline Questionnaire on hand hygiene & Healthcare workers & 1 \\
\hline
\end{tabular}

a Campaigns number 1, 2, 3, and 4 respectively took place in 2005, 2006, 2009, and 2011.

b The second version had more emphasis on patient empowerment.

The campaign slogan was: 'You are in good hands'.

d The number of modules was gradually expanded, including modules specifically targeted at physicians, physiotherapists and healthcare workers in psychiatric hospitals. 
Measurement of hand hygiene compliance of healthcare workers by direct observation Compliance to hand hygiene guidelines was measured by the IC teams by direct observation using a standardised observation roster [11]. The opportunities for hand hygiene were counted and the actual episodes of hand hygiene were scored as hand hygiene with alcohol-based hand rub, hand hygiene with water and soap or no hand hygiene [12]. Compliance was stratified by indication (before patient contact, after patient contact, before an aseptic task, after body fluid exposure risk, after contact with patient surroundings) and by type of HCW (nurses, nursing assistants, physicians, physiotherapists, other). Thus, the metric used was the number of episodes divided by the number of opportunities. For each hospital unit included in the compliance survey, at least 150 opportunities had to be monitored both before and after the intervention period. Inclusion of the intensive care unit (ICU) was mandatory for the acute care hospitals, but otherwise the institutions were free to include any number or any type of (additional) hospital units in the compliance survey. If the hospitals sent their compliance data immediately to the IPH as suggested, they received feedback with benchmarking, defined as the position of the hospital in the national distribution, within a few days, allowing the IC teams to use this information as performance feedback to motivate HCWs in their institution.

\section{Data management and statistical analysis}

Data on hand hygiene compliance were entered in NSIHwin (MS Access application) [13], a software tool for data entry developed by the IPH and provided free of charge to participating institutions. This software tool also allows the user to generate some automatic reports for the hospital in question. Data from individual hospitals could be sent to the IPH to be appended to a national database. All data were processed and analysed using Stata 10.0 software. National results are given as a weighted mean, thus adjusting for varying numbers of observations between hospitals.

\section{Results}

Participation rates were good to excellent for the different types of hospitals, with at least $92 \%$ of acute care hospitals involved in each campaign, and at least $61 \%$ of chronic care hospitals and at least $61 \%$ of psychiatric hospitals, respectively (Table 2).

A total of 149,041 opportunities for hand hygiene $(74,581$ before and 74,460 after the intervention period) were observed during the first campaign, 196,685 (111,176 before and 85,509 after) during the second campaign, 223,719 (111,476 before and 112,243 after) during the third campaign, and 168,922 (89,553 before and 79,369 after) during the fourth campaign.

After each respective campaign, compliance with hand hygiene (national weighted mean for all hospital sites combined) increased significantly (p<0.05), from $49.6 \%$ before to $68.6 \%$ after the intervention for the first campaign (absolute increase in compliance rate, $+19.0 \%$ ), from $53.2 \%$ to $69.5 \%$ for the second campaign $(+16.3 \%)$, from $58.0 \%$ to $69.1 \%$ for the third campaign $(+11.1 \%)$, and from $62.3 \%$ to $72.9 \%$ for the fourth campaign (+10.6\%).

The increase in compliance rates was observed in acute care hospitals, chronic care hospitals and psychiatric hospitals (Figure and Table 3). A wide distribution of the compliance rates of the different participating hospitals could be noticed (Figure).

Similarly to what could be observed at the hospitals and hospital type levels, compliance rates also improved significantly for all types of hospital units (p<0.05), with the highest compliance rates consistently being observed in paediatric units. Compliance rates were lowest for rehabilitation units during the first and fourth campaign and for surgical units during the second and third campaign.

Although compliance rates increased for all types of $\mathrm{HCWs}$, it is remarkable that compliance was markedly lower (absolute difference in compliance rate, $-13 \%$ to $-20 \%$, p 0.05 ) among physicians than nurses.

Compliance increased for all indications for hand hygiene but was much higher (absolute difference in compliance rate, often $+20 \%$, p $<0.05$ ) after patient contact and body fluid exposure risk than before patient

TABLE 2

Participation rate per type of hospital for four Belgian hand hygiene campaigns, Belgium, 2005-2011

\begin{tabular}{|l|c|c|c|c|} 
& $\begin{array}{c}\text { Campaign 2005 } \\
\text { n/N (\%) }\end{array}$ & $\begin{array}{c}\text { Campaign 2006 } \\
\text { n/N (\%) }\end{array}$ & $\begin{array}{c}\text { Campaign 2009 } \\
\text { n/N (\%) }\end{array}$ & $\begin{array}{c}\text { Campaign 2011 } \\
\text { n/N (\%) }\end{array}$ \\
\hline Acute care hospitals & $112 / 116(97 \%)$ & $113 / 116(97 \%)$ & $110 / 113(97 \%)$ & $98 / 107(92 \%)$ \\
\hline Chronic care hospitals & $19 / 31(61 \%)$ & $22 / 30(73 \%)$ & $20 / 28(71 \%)$ & $16 / 24(67 \%)$ \\
\hline Psychiatric hospitals $^{\mathrm{a}}$ & $\mathrm{NA}$ & $43 / 68(63 \%)$ & $46 / 67(69 \%)$ & $41 / 67(61 \%)$ \\
\hline All hospitals & $131 / 147(89 \%)$ & $178 / 214(83 \%)$ & $175 / 208(84 \%)$ & $156 / 198(79 \%)$ \\
\hline
\end{tabular}

NA: Not available.

a Psychiatric hospitals were invited to participate in the study from the second campaign forth. 


\section{FIGURE}

Distribution of compliance rates for acute care, chronic care and psychiatric hospitals ${ }^{\mathrm{a}}$ and for all hospital types combined before and after the Belgian hand hygiene campaigns, 2005-2011
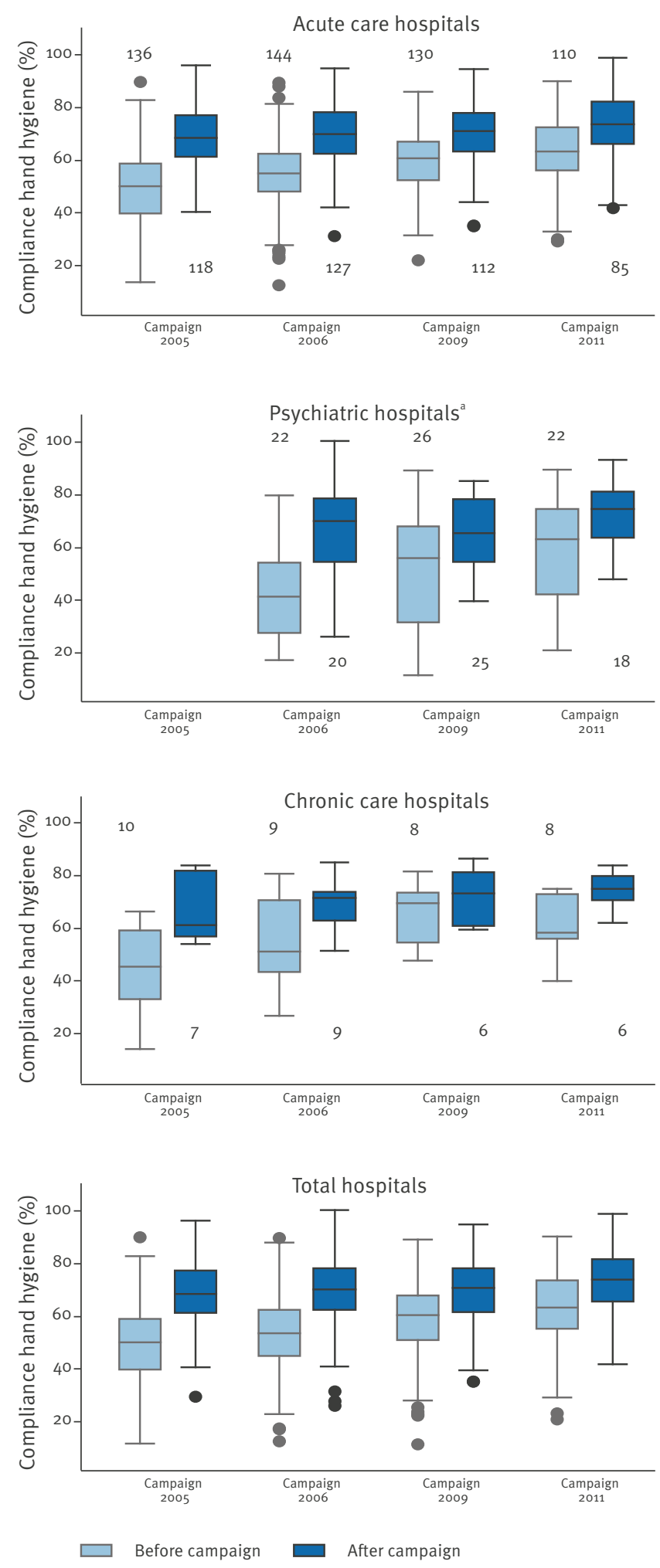

The median (horizontal line in a box), inter-quartile range (box hight), as well as maximum and minimum limits (vertical whiskers) of the compliance rates are shown, as well as outliers (dots). The numbers above and below the box plots are the number of hospital sites that provided their compliance data to the Scientific Institute of Public Health.

a Psychiatric hospitals were invited to participate in the study from the second campaign onwards. contact and aseptic tasks, with compliance after contact with surroundings of patient somewhere in the middle (Table 3).

Overall, compliance with hand hygiene improved over the four campaigns. Furthermore, this improvement was partially sustained between campaigns: although compliance before the second, third and fourth campaign was lower than after the previous campaign, it was clearly higher than before the previous campaign. However, while before campaign compliance rates are steadily increasing over time from $49.6 \%$ to $62.3 \%$, after campaign compliance rates seem to stabilise around $70 \%$.

\section{Discussion}

In our study an increase in hand hygiene compliance was observed after each individual campaign to promote hand hygiene. Comparing the effect of the four campaigns over time also yielded an increased rate of compliance for all hospitals combined. The increase of compliance at the end of each campaign seemed to be partially sustained until the beginning of the next campaign. Although this suggests that the repeated campaigns resulted in an overall progressive improvement of hand hygiene, it is noteworthy that the participating hospitals may have varied between each campaign. The increase in hand hygiene compliance, however, was also observed for each type of hospitals, some of which, such as acute care hospitals, had a very high participation rate (over $92 \%$ ). In this case, the hospitals participating in the different campaigns could not have varied much. The need for sustained or repeated interventions to obtain prolonged or permanent effects has moreover been documented previously $[6,7,14,15]$.

The observation of a wide distribution of hand hygiene compliance rates of the different participating hospitals in this study can be partly explained by the type of hospital, the inclusion of different types of hospital units for measuring compliance, and inter-observer variability, but undoubtedly represents real differences between hospitals.

While the lower compliance to hand hygiene for physicians than for nurses confirms the findings of other authors [6,9,14-17], a study by Salemi et al. [18] shows that improvement of hand hygiene compliance among physicians is feasible.

That hand hygiene compliance for HCW is higher after patient contact and body fluid exposure than before patient contact and aseptic tasks has also been reported by others $[6,9,14]$. One explanation could be that HCWs are more inclined to protect themselves than their patients. Another possible interpretation is that HCWs are more likely to decontaminate their hands if they perceive them to be dirty [19].

Based on this study, the working group plans to repeat these national campaigns every two years with the 
fifth campaign scheduled for 2012-13. This forthcoming campaign will focus on hand hygiene before patient contact and aseptic tasks. Raising awareness among physicians of the importance of this deceptively simple but crucial act also remains a priority. However, it could be that our national campaign approach, which is limited in time and not perfectly adapted to each specific setting, has reached its limits and that continuous initiatives more suited to the specific setting are needed to breach the ceiling of $70 \%$ compliance.

In 2009, twelve other European countries had also organised countrywide campaigns to promote hand hygiene [20]. However, national data demonstrating the impact of these campaigns on hand hygiene compliance and/or consumption of alcohol based hand rub solutions were not often collected or are not yet published. In fact, published data are at present only available for the United Kingdom: the NOSEC study (National Observational Study to Evaluate the cleanyourhands campaign) demonstrated a rise in the combined median use of alcohol-based hand rubs and soap from 13.2 to $31 \mathrm{~mL} /$ patient-bed-day, but there were no changes in HAI rates [21].

As with most studies in this research field, our study has several limitations. First, we used an uncontrolled before-and-after design so as to implement the campaign in a maximum number of institutions (no control group at the hospital level); and to limit the workload of the IC teams, we did not include control units (no control group at the hospital unit level). Second, although direct observation is considered the most appropriate method for measuring hand hygiene compliance rates, it still has several drawbacks including the 'Hawthorne effect', concerns with inter-observer reliability, and the fact that it only represents a sample of all hand hygiene opportunities $[22,23]$. Third, rates of HAls were not evaluated. On the other hand, several studies have demonstrated a link between improvement of hand hygiene compliance and reduction of methicillin-resistant Staphylococcus aureus (MRSA)

\section{TABLE 3}

Compliance rate per type of hospital, type of hospital unit, type of healthcare worker and indication for hand hygiene during four Belgian hand hygiene campaigns, Belgium, 2005-2011

\begin{tabular}{|c|c|c|c|c|c|c|c|c|}
\hline & \multicolumn{8}{|c|}{ Hand hygiene compliance (\%) } \\
\hline & \multicolumn{2}{|c|}{ Campaign 2005} & \multicolumn{2}{|c|}{ Campaign 2006} & \multicolumn{2}{|c|}{ Campaign 2009} & \multicolumn{2}{|c|}{ Campaign 2011} \\
\hline & Before & After & Before & After & Before & After & Before & After \\
\hline \multicolumn{9}{|l|}{ Type of hospital } \\
\hline All types & 49.6 & 68.6 & 53.2 & 69.5 & 58.0 & 69.1 & 62.3 & 72.9 \\
\hline Acute care & 50.4 & 69.0 & 54.8 & 70.2 & 58.9 & 69.8 & 63.2 & 73.1 \\
\hline Chronic care & $45 \cdot 5$ & 67.6 & 56.6 & 70.0 & 66.0 & 72.9 & 61.6 & 74.7 \\
\hline Psychiatric & - & - & 43.3 & 64.8 & 52.2 & 65.4 & 58.9 & 72.6 \\
\hline \multicolumn{9}{|l|}{ Type of hospital unit } \\
\hline Intensive care unit & 52.6 & 68.9 & 58.9 & 70.4 & 62.3 & 70.1 & 66.9 & 74.5 \\
\hline Surgery & 49.5 & 69.6 & 51.4 & 65.7 & $55 \cdot 7$ & 67.5 & 61.4 & 70.7 \\
\hline Internal medicine & 47.7 & 67.5 & 53.9 & 70.6 & 62.1 & 69.8 & 61.3 & 70.3 \\
\hline Paediatrics & 60.1 & 76.1 & 65.8 & 76.9 & 65.7 & 74.4 & 71.2 & 80.4 \\
\hline Geriatrics & 48.2 & 71.9 & $55 \cdot 3$ & 70.7 & 58.4 & 70.1 & 60.5 & 71.0 \\
\hline Rehabilitation & 42.2 & 64.7 & 53.8 & 69.4 & 61.3 & 70.1 & 58.2 & 67.3 \\
\hline \multicolumn{9}{|l|}{ Type of healthcare worker } \\
\hline Nurse & $54 \cdot 4$ & 72.3 & $57 \cdot 3$ & 73.2 & 61.7 & 73.2 & 66.2 & 76.9 \\
\hline Nursing assistant & 44.4 & $67 \cdot 3$ & 51.1 & 66.7 & 57.1 & 68.5 & 62.5 & 71.8 \\
\hline Physician & 37.6 & 54.1 & 42.2 & 54.4 & $45 \cdot 7$ & 54.0 & 53.0 & 57.1 \\
\hline Physiotherapist & 48.7 & 66.3 & 52.8 & 67.4 & 54.6 & 64.7 & 61.8 & 69.0 \\
\hline Other & 33.2 & 61.4 & 40.2 & 56.5 & 48.8 & 58.0 & 52.6 & 63.8 \\
\hline \multicolumn{9}{|l|}{ Indication for hand hygiene } \\
\hline Before patient contact & 35.9 & 56.6 & 39.0 & 57.0 & 44.2 & 56.8 & 50.2 & 62.7 \\
\hline After patient contact & 60.3 & 78.5 & 62.9 & 76.4 & 66.9 & 76.7 & 71.3 & 79.5 \\
\hline Before aseptic task & 37.7 & 54.9 & 42.2 & 60.6 & 46.9 & 60.0 & 50.7 & 62.8 \\
\hline After body fluid exposure risk & 61.4 & 76.4 & 65.0 & 79.6 & 69.1 & 78.9 & 72.8 & 82.9 \\
\hline After contact with surroundings of patient & 47.8 & 68.2 & 49.6 & 66.6 & 53.9 & 64.8 & $57 \cdot 3$ & 69.3 \\
\hline
\end{tabular}

All differences between compliance rates before and after each campaign are statistically significant ( $<<0.05)$. 
bacteraemia or HAI rates [24-30]. Finally, hand hygiene technique was not used as an outcome measure since standardised evaluation of this qualitative aspect is extremely difficult, especially when so many observers are involved [23].

On the other hand, our study has several unique strengths. It is the first publication of an intervention to improve hand hygiene on such a large countrywide scale, with a grand total of 738,367 opportunities observed. Furthermore, the scope is unprecedented with the participation of acute care, chronic care and psychiatric hospitals, and the observation of all types of HCWs over a broad range of different hospital units. Finally, we provide data for four successive campaigns over a six-year period.

We conclude that countrywide campaigns to promote hand hygiene are feasible and have positive short term and long term results when they are repeated regularly.

\section{Acknowledgements}

We would like to thank all present and former members of the Belgian hand hygiene campaign working group: Anne Simon (president), Christophe Barbier, Michiel Costers, Stijn De Corte, Francine De Meerleer, David De Wandel, Norbert Eggermont, Bart Gordts, Roger Haenen, Eva Leens, Karl Mertens, Aldo Spettante, Carl Suetens, Patricia Taminiau, Sofie Vaerenberg, Mia Vande Putte, Irène Vanden Bremt, Evelyne Van Gastel, Magda Vanneste, An Willemse.

\section{References}

1. Gordts B, Vrijens F, Hulstaert F, Devriese S, Van De Sande S. The 2007 Belgian national prevalence survey for hospitalacquired infections. J Hosp Infect. 2010;75(3):163-7.

2. Vrijens F, Hulstaert F, Gordts B, De Laet C, Devriese S, Van De Sande S, et al. Nosocomial infections in Belgium, part II: impact on mortality and costs. Health Services Research (HSR). Brussels: Belgian Health Care Knowledge Centre (KCE); 2008. KCE reports 92C (D/2008/10.273/72).

3. Pittet D, Allegranzi B, Sax H, Dharan S, Pessoa-Silva $\mathrm{CL}$, Donaldson L, et al. Evidence-based model for hand transmission during patient care and the role of improved practices. Lancet Infect Dis. 2006;6(10):641-52.

4. Boyce JM, Pittet D, Healthcare Infection Control Practices Advisory Committee; HICPAC/SHEA/APIC/IDSA Hand Hygiene Task Force. Guideline for hand hygiene in health-care settings: Recommendations of the Healthcare Infection Control Practices Advisory Committee and the HICPAC/SHEA/APIC/IDSA hand hygiene task force. Society for Healthcare Epidemiology of America/Association for Professionals in Infection Control/ Infectious Diseases Society of America. MMWR Recomm Report. 2002;51(RR-16):1-45.

5. World Health Organization (WHO). WHO guidelines on hand hygiene in health care. First Global Patient Safety Challenge. Clean Care is Safer Care. Geneva: WHO; 2009. Available from: http://whqlibdoc.who.int/publications/2009/9789241597906 eng.pdf

6. Pittet D, Hugonnet S, Harbarth S, Mourouga P, Sauvan $V$, Touveneau S, et al. Effectiveness of a hospital-wide programme to improve compliance with hand hygiene. Infection Control Programme. Lancet. 2000;356(9238):1307-12.

7. Naikoba S, Hayward A. The effectiveness of interventions aimed at increasing handwashing in healthcare workers - a systematic review. J Hosp Infect. 2001;47(3):173-80.

8. Gould DJ, Chudleigh JH, Moralejo D, Drey N. Interventions to improve hand hygiene compliance in patient care. Cochrane Database Syst Rev. 2007;(2):CDo05186.

9. Erasmus V, Daha TJ, Brug H, Richardus JH, Behrendt MD, Vos MC, et al. Systematic review of studies on compliance with hand hygiene guidelines in hospital care. Infect Control Hosp Epidemiol. 2010;31(3):283-94.

10. Federal Public Service Public Health, Food Chain Safety and Environment. Hygiène des mains [Hand hygiene]. Brussels: Federal Public Service Public Health, Food Chain Safety and Environment. French. [Accessed 27 Apr 2012]. Available from: http://www.health.belgium.be/eportal/ Healthcare/Healthcarefacilities/HospitallnfectionControl/ FEDERALPLATFORM/Handhygienics/index.htm?\&fodnlang=fr

11. Pittet D, Mourouga P, Perneger TV. Compliance with handwashing in a teaching hospital. Ann Intern Med. 1999;130(2):126-30.

12. Sax H, Allegranzi B, Uckay I, Larson E, Boyce J, Pittet D. 'My five moments for hand hygiene': a user-centred design approach to understand, train, monitor and report hand hygiene. J Hosp Infect. 2007;67(1):9-21.

13. Scientific Institute of Public Health - Public health and surveillance. Healthcare Associated Infections (NSIH). NSIHwin Download Pagina [NSIHwin Download Page]. Brussels: NSIH. [Accessed 27 Apr 2012]. Dutch. Available from: www.nsih.be

14. Hugonnet S, Perneger TV, Pittet D. Alcohol-based handrub improves compliance with hand hygiene in intensive care units. Arch Intern Med. 2002;162(9):1037-43.

15. Rosenthal VD, McCormick RD, Guzman S, Villamayor C, Orellano PW. Effect of education and performance feedback on handwashing: The benefit of administrative support in Argentinean hospitals. Am J Infect Control. 2003;31(2):85-92.

16. Earl ML, Jackson MM, Rickman LS. Improved rates of compliance with hand antisepsis guidelines: A three-phase observational study. Am J Nurs. 2001;101(3):26-33.

17. Panhotra BR, Saxena AK, Al-Arabi Al-Ghamdi AM. The effect of a continuous educational program on handwashing compliance among healthcare workers in an intensive care unit. Br J Infect Control. 2004;5(3):15-8.

18. Salemi C, Canola MT, Eck EK. Hand washing and physicians: how to get them together. Infect Control Hosp Epidemiol. 2002;23(1):32-5.

19. van der Vegt DS, Voss A. Are hospitals too clean to trigger good hand hygiene? J Hosp Infect. 2009;72(3):218-20.

20. Magiorakos AP, Suetens C, Boyd L, Costa C, Cunney R, Drouvot $\mathrm{V}$, et al. National hand hygiene campaigns in Europe, 2000-2009. Euro Surveill. 2009;14(17): pii=19190. Available from: http://www.eurosurveillance.org/ViewArticle. aspx?Articleld $=19190$

21. Stone S, Slade R, Fuller C, Charlett A, Cookson B, Teare L, et al. Early communication: Does a national campaign to improve hand hygiene in the NHS work? Initial English and Welsh experience from the NOSEC study (National Observational Study to Evaluate the CleanYourHandsCampaign). J Hosp Infect. 2007;66(3):293-6.

22. Haas JP, Larson EL. Measurement of compliance with hand hygiene. J Hosp Infect. 2007;66(1):6-14.

23. Gould DJ, Chudleigh J, Drey NS, Moralejo D. Measuring handwashing performance in health service audits and research studies. J Hosp Infect. 2007;66(2):109-15.

24. Swoboda SM, Earsing K, Strauss K, Lane S, Lipsett PA. Electronic monitoring and voice prompts improve hand hygiene and decrease nosocomial infections in an intermediate care unit. Crit Care Med. 2004:32(2):358-63.

25. Lam BC, Lee J, Lau YL. Hand hygiene practices in a neonatal intensive care unit: A multimodal intervention and impact on nosocomial infection. Pediatrics. 2004;114(5):e565-71.

26. Won SP, Chou HC, Hsieh WS, Chen CY, Huang SM, Tsou KI, et al. Handwashing program for the prevention of nosocomial infections in a neonatal intensive care unit. Infect Control Hosp Epidemiol. 2004;25(9):742-6.

27. Johnson PD, Martin R, Burrell LJ, Grabsch EA, Kirsa SW, O'Keeffe J, et al. Efficacy of an alcohol/chlorhexidine hand hygiene program in a hospital with high rates of nosocomial methicillin-resistant Staphylococcus aureus (MRSA) infection. Med J Aust. 2005;183(10):509-14.

28. Rosenthal VD, Guzman S, Safdar N. Reduction in nosocomial infection with improved hand hygiene in intensive care units of a tertiary care hospital in Argentina. Am J Infect Control. 2005;33(7):392-7.

29. Pessoa-Silva CL, Hugonnet S, Pfister R, Touveneau S, Dharan S, Posfay-Barbe K, et al. Reduction of health care-associated infection risk in neonates by successful hand hygiene promotion. Pediatrics. 2007;120(2):e382-90.

30. Grayson ML, Jarvie LJ, Martin R, Johnson PD, Jodoin ME, McMullan C, et al. Significant reductions in methicillinresistant Staphylococcus aureus bacteraemia and clinical isolates associated with a multisite, hand hygiene culturechange program and subsequent successful statewide roll-out. Med J Aust. 2008;188(11):633-40. 